\title{
Clinical Findings and Demography of Retinoblastoma in a Tertiary Hospital in a Remote Area in a Developing Country
}

\author{
Golda Asina Miranda ${ }^{1}$, Gilbert W S Simanjuntak ${ }^{2}$
}

${ }^{1}$ Department of Ophthalmology North Sumatera University, Medan, Indonesia. ${ }^{2}$ Department of Ophthalmology Christian University of Indonesia, Jakarta, Indonesia.

\begin{abstract}
Purpose: To report clinical characteristics and demography of retinoblastoma managed in a tertiary eye hospital in a remote area in a developing country. Methods: This is a descriptive retrospective study. Clinical characteristics were gender, age, tumor growth, onset, severity, laterality, nutritional status, and prominent clinical signs. The socioeconomic demographics of the patient's families were grouped into work and economic conditions, and education. Management and its outcome were recorded. Results: There were 91 samples, distributed evenly in five years. The frequency was even between middle income 45 patients (49.5\%) and lower middle income 46 patients $(50.5 \%)$. The mean age at diagnosis was $3-5$ year with 49 patients $(53,8 \%)$, ranging from 1 to 12 years. Male to female ratio was $1: 1$. Less nutritional status were 64 patients $(70.3 \%)$. All cases occurred unilaterally without family history of RB, and laterality was equal between right and left eye, with 1:1 ratio. Those patients who mainly presented with extra ocular involvement numbered 73 patients $(80.2 \%)$ and those with clinical symptoms of protruded numbered 70 patients $(76.9 \%)$. Patients generally presented in stage IV of 70 cases (76.9\%). The mean onset was $1-2$ years in 43 cases $(47.2 \%)$. The therapeutic management was chemotherapy. After treatment, all patients followed up in two weeks. Conclusion: RB patients referred to a tertiary hospitalin a remote area are more likely to come in advanced stage, from middle-income group parents. More extraocular cases seen with major clinical features of protruded eye with an onset of 2-3 years.
\end{abstract}

Keywords: Retinoblastoma- sociodemography- developing country

Asian Pac J Cancer Care, 3 (2), 37-41

\section{Introduction}

Retinoblastoma (RB) is the most prevalent intraocular malignancy that commonly affects children $<3$ years of age, but may also appear at $>5$ years of age $[1,2]$. This malignancy can end up with blindness or death if not diagnosed early. The RB incidence varies according to the sociodemographics of each country [3-5] Parental education, low socioeconomic conditions, and inadequate health facilities may result in delays of diagnosis and management of RB in developing countries. In developed countries such as America, Britain, and other European countries, this malignancy is diagnosed earlier in childhood $<2$ years [6].

The RB incidence is 1: $15.000-20.000$ per birth rate. This cancer generally occurred unilaterally, the mean age when diagnosed was two years in $60 \%$ of cases [4].
Submission Date: 02/18/2018Ａcceptance Date: 05/19/2018

The World Health Organization (WHO), in 18 February 1999, promoted The Right to Sight program to eliminate childhood blindness so that childhood blindness rates would decline by 2020 [5].

In developed countries with high levels of community education, optimal health facilities, and good socioeconomic conditions; RB was diagnosed with early clinical manifestations. In these countries patients generally come with intraocular tumor manifestation with clinical manifestations of cat eye (leukokoria), strabismus, and decrease of vision [7]. In developing countries, however, $60-90 \%$ patients come with extraocular tumor manifestation with clinical manifestations of prominent eye (proptosis), orbital cellulitis, corneal perforation, and stem mass [8].

The RB classification affects preliminary management, outcome prediction, and prognose [9]. The first RB

Corresponding Author:

Dr. Gilbert W S Simanjuntak

Department of Ophthalmology Christian University of Indonesia, Jakarta, Indonesia.

Email: retinaid@yahoo.com 
classification of Reese-Ellsworth (1950) transformed into the International Intraocular Retinoblasma (IIRC) classification (2003) that emphasized chemotherapy and focal lasers, and provided better treatment outcomes. (Deng,2013) This increase in the therapeutic success rate, and visual outcome of patients improved significantly in developed countries compared to developing countries [10] The therapeutic success rate and visual outcome of patients in developing countries are low due to late diagnosis along with poor clinical conditions when patients are treated [11].

The tertiary hospital in Medan, Indonesia, covered a remote area. As a consequence, most RB patients were in the advanced stage of their condition. The purpose of this study is to report clinical characteristics and demographics, of retinoblastoma patients, from a tertiary hospital covering a remote area in a developing country.

\section{Materials and Methods}

This is a descriptive study using total samplings. The population and sample of this study were all patients who were diagnosed with retinoblastoma at Adam Malik Hospital, Medan, January 2011 to December 2016. The data was obtained from medical records of RB patients. The North Sumatera University Institutional Ethics Committee granted approval for this study following the tenets of the Declaration of Helsinki. Patients without treatment were not included in the study.

Torch or slit lamp examination (if possible) was done carefully to look for any significant anterior segment findings. Initial and final visual acuity, and eye movement were checked during this examination. Any extra ocular findings were recorded. The pupil was dilated with tropicamide $0,5 \% \mathrm{ED}$, dropped twice in 5 minutes intervals. The funduscopic examination was done, and any findings were drawn on medical record. The therapeutic management was recorded. The therapeutic management was surgery, chemotherapy, radiotherapy or a combination; and the outcomes were recorded.

Sociodemographics of the elderly were listed in the medical record and grouped as lower, middle, and upper class. The nutritional status was assessed from the body mass index or the surface area of the body listed in the medical record.The nutritional status was classified into three categories namely, malnourished, normal, or obese. The severity was the order of severity of an illness based on the criteria using the RBD Resse-Ellsworth classification. The clinical symptoms are characteristic symptoms that appeared and include the doctor's diagnosis and parents' complaint as written in the medical record. The onset was the duration of clinical symptoms that appeared until the child was taken by his/her parents to the doctor. The outcome was the final result that describes the level of success of the management. In this study, we determined to follow up at least 1 week after therapy since almost all patients had follow-up 1 week then back to the remote are, and recorded whether the patient lived or died. All patients were included in analysis. SPSS version 24.0
(SPSS, Inc., Chicago, IL) was used.

\section{Result}

There were 129 new cases of retinoblastoma coming to Adam Malik Hospital Medan during the period of January 2011 - December 2016. A total of 91 patients met the inclusion criteria, while the other 38 patients were not eligible because of incomplete medical record data. These eligible patients came from remote areas.

Distribution of patients per year for 5 years was relatively even (between $12-23 \%$ ), with distribution 14 patients $(15.4 \%)$ in 2011,11 patients $(12.1 \%)$ in 2012 , 21 patients $(23.1 \%)$ in 2013,17 patients $(18.7 \%)$ in 2014 , 12 patients (13.25) in 2015, and 12 patients (13.2\%) in 2016. The frequencies in 2013 were higher, but cannot be explained because there was no further information in the medical record.

Based on sociodemographic data, the frequency was even between 45 middle income patients $(49.5 \%)$ and 46 lower middle income patients $(50.5 \%)$. The mean age at diagnosis was 3-5 year for 49 patients $(53.8 \%)$, ranging from 1 to 12 years. Male to female ratio was 1:1.

The majority of the 64 patients $(70.3 \%)$ suffered maltnutrion. There was no family history of RB, and all cases occurred unilaterally. The laterality was equal between right or left eye, with 1:1 ratio. The majority of the patients presenting with extra ocular involvement was 73 patients $(80.2 \%)$ while the clinical symptom of protruded eye was 70 patients $(76.9 \%)$. Patients generally presented in stage IV of 70 cases $(76.9 \%)$. The mean onset was 1-2 years in 43 cases $(47.2 \%)$. The therapeutic management was the chemotherapy method of Vincristine (VCR), Etoposide (EPO), Carboplatin (CPA) in 39 cases $(42,9 \%)$. The patient's

outcome was measured as still living in 89 cases $(97.8 \%)$ after following up at a minimum of one week. After the treatment, all patients followed up in less than two weeks, they return back to remote area. Details are shown in Table 1.

The patients with onset $<1$ year mainly presented with the intra ocular clinical symptom of cat eye: 13 patients $(21.9 \%)$. Patients with onset $>1$ year presented as extra ocular cases with the clinical symptom of protruded eye in 28-29 patients. There is no record of tumors size and fundus photo was not done as a tool to perform documentation, so details of the tumor are difficult to obtain.

The longer the onset, the more severe were the appearances of the clinical symptoms. None of the cases underwent evisceration or enucleation because of the late stage of the tumors and the parents refused the treatment because they feared facing their child's disfiguration without an eye. Details are shown in Table 2.

\section{Discussion}

This is a descriptive study to report the characteristics of retinoblastoma patients at Adam Malik Hospital Medan from January 2011 to December 2016. There were 129 
Tabel 1. Demography and Clinical Characteristic of Retinoblastoma, Adam Malik Hospital Medan

\begin{tabular}{|c|c|c|}
\hline Characteristic & Number & $\%$ \\
\hline \multicolumn{3}{|l|}{ Social Status } \\
\hline -lower & 45 & 49.5 \\
\hline -middle & 46 & 50.5 \\
\hline -upper & 0 & 0 \\
\hline \multicolumn{3}{|l|}{ Age (year) } \\
\hline$<3$ & 32 & 35.2 \\
\hline $3-5$ & 49 & 53.8 \\
\hline$>5$ & 10 & 11 \\
\hline \multicolumn{3}{|l|}{ Nutritional status } \\
\hline less & 64 & 70.3 \\
\hline normal & 27 & 29.7 \\
\hline obese & 0 & 0 \\
\hline \multicolumn{3}{|l|}{ Tumor growth } \\
\hline intraocular & 18 & 19.8 \\
\hline extraocular & 73 & 80.2 \\
\hline $\operatorname{mix}$ & 0 & 0 \\
\hline \multicolumn{3}{|l|}{ Severity: } \\
\hline stadium 1 & 20 & 22 \\
\hline stadium 2 & 0 & 0 \\
\hline stadium 3 & 1 & 1.1 \\
\hline stadium 4 & 70 & 76.9 \\
\hline \multicolumn{3}{|l|}{ Prominent clinical sign } \\
\hline cat eye & 20 & 22 \\
\hline swelling & 1 & 1.1 \\
\hline protruded eye & 70 & 76.9 \\
\hline \multicolumn{3}{|l|}{ Therapy } \\
\hline Bone Marrow Puncture & 15 & 16.5 \\
\hline Exenteration & 1 & 1.1 \\
\hline Enucleation & 22 & 24.2 \\
\hline Chemmotherapy CPA & 1 & 1.1 \\
\hline Chemotherapy CPA/EPO & 11 & 12.1 \\
\hline Chemotherapy MTX & 1 & 1.1 \\
\hline Chemotherapy VCR/CPA & 1 & 1.1 \\
\hline Chemotherapy VCR/CPA/EPO & 39 & 42.9 \\
\hline \multicolumn{3}{|l|}{ Outcome } \\
\hline live & 89 & 97.8 \\
\hline death & 2 & 2.2 \\
\hline
\end{tabular}

new patients of RB, 91 patients (91 eyes) fulfilling the inclusion criteria, while 38 patients were excluded because of incomplete data.

The RB incidence varies according to the sociodemographics of each country. In this study, 49 patients presented at 3-5 years of age $(53.8 \%)$. There were 46 patients $(50.5 \%)$ with parents of middle social status, and 45 patients (49.5\%) with middle to low social status. In developed countries such as America, Britain, and other European countries, this malignancy is diagnosed earlier in childhood less $<2$ years $[5,6]$. In developing countries, $\mathrm{RB}$ is diagnosed in older children.
The same conditions are found in Indonesia. In this study patients presented at an older age and sociodemographic background. There was no difference between middle and lower middle class patients.

In this study, more patients fell into the malnourished category at 64 patients $(70.3 \%)$. The patients with solid tumors have an increase in basal metabolic rates of up to $50 \%$ and this is related to decreased nutritional status and the type and size of tumors. In patients with solid tumors, major changes occured in fat metabolism followed by weight loss, largely due to the depletion of body fat [12]. Compared with adults, children have a greater risk of nutritional deficiencies due to their faster basal metabolics associated with growth and development. This contributes to the deterioration of the patient's nutritional status in this study [13].

In this study, there were 47 male patients $(51.6 \%)$ and 44 female patients $(48.4 \%)$. A study of Soetomo Hospital (2010), Surabaya, Indonesia also reported no gender difference in RB disease [14], but the other study at the same place [15] found more males at $27(61.3 \%)$, and than women at $17(38.6 \%)$. In general, the ratio of men to women with retinoblastoma is unknown [16]Other studies reported that there is no racial or gender predisposition to the incidence of retinoblastoma [8]. This malignancy is more commonly found and acquired (94\%), as opposed to hereditary (6\%). Knudson (1971) states that RB occurs due to mutations of two chromosomes: the germinal chromosome and the somatic chromosome. In hereditary $\mathrm{RB}$, the initial mutation of germinal chromosomes is found throughout the cell, and a second mutation of somatic chromosomes occurred in retinal cells. In the acquired RB, the two mutations derived from somatic cells $[2,8]$. In this study, all cases were acquired RB, with no family history. There is no record of tumors size and fundus photos were not done as a tool to perform documentation, so details of the tumor are difficult to obtain. Documentation of tumor size or comparing with an optic nerve head unfortunately was not done.

Retinoblastoma was reported more frequently unilaterally sporadic $(60 \%)$ rather than bilaterally hereditary (40\%) [17, 18] Patients with bilateral retinoblastoma are assumed to have germinal cell mutations (100\% hereditary), although genetic testing cannot identify these cell mutations (encountered in about $5 \%$ of cases). Hereditary (bilateral) RB was diagnosed at a younger mean age, 12-15 months; while acquired RB diagnosed at an older mean age, 24 months [17]. In this study, all patients with unilateral retinoblastoma had a mean age of 42 months. The delay

Table 2. Onset Distribution by Age with Clinical Signs

\begin{tabular}{lccc}
\hline Onset (year) & Cat Eye & Protruded Eye & Total \\
\hline$<1$ & 13 & 7 & 20 \\
$1-2$ & 7 & 28 & 35 \\
$2-3$ & 0 & 29 & 29 \\
$>3$ & 1 & 6 & 7 \\
& 21 & 70 & 91 \\
\hline
\end{tabular}


was related to the sociodemographic background of the patient's parents and that of the patient's origin from a remote area. Even if the patient presented late, there is inadequate management. For example there is no documentation whether there is a reduction of the tumor or proptosis after treatment. Economic conditions make it difficult for patients and parents to stay in big cities. They return to the remote area soon after the treatment is completed, expecting further follow-up to be done in the remote area without any ophthalmologist and equipment.

In this study, more patients presented with extraocular clinical features $(80.2 \%)$, with clinical manifestation proptosis in 70 patients (76.9\%), in stage IV. In developed countries, patients generally present with intraocular tumor, $[5,7]$ with clinical manifestations of cat eye (leukokoria), strabismus, and decrease of vision whereas, in developing countries, $60-90 \%$ of patients come with extraocular clinical features, with clinical manifestations of proptosis, orbital cellulitis, corneal perforation, and stem mass $[8,17]$. In this study, patients with extraocular clinical features were associated with delayed diagnosis with an onset of $1-2$ years at 43 people (47.2\%). A similar clinical picture was reported by [14], in which patients came in withextraocular clinical features $(60 \%)$ at $6-12$ months onset $(25 \%)$. This occurred due to limited access to adequate health facilities, lack of education and the parent's socioeconomical situation. Since all these cases were already in an advance stage with a very poor prognosis, it can be presumed that these patients were less likely to follow-up because of death.

The RB Classification influences early management, outcome prediction, and prognosis. The first RB classification of Reese-Ellsworth (1950) predicts the outcome based on external-beam radiotherapy (EBRT); whereas, the International Intraocular Retinoblasma (IIRC) classification (2003) focuses on outcomes based on chemotherapy and focal lasers. Management of intraocular RB includes enucleation, chemotherapy, EBRT, and focal therapy (cryotherapy, laser photocoagulation, thermotherapy, brachytherapy I125). Based on IIRC, selected treatment of RB group B-D is using intravenous chemotherapy followed by focal therapy; whereas, the best treatment for unilateral RB group $\mathrm{D}$ is by enucleation $[10,19]$ The classification of RB used in Adam Malik Hospital Medan was unknown based on medical records; therefore, the main management reasons applied to the patient are accordingly unknown. None of these cases underwent evisceration or enucleation because of the tumor's late stage and the parents refusal due to their fear of facing their child's condition without an eye. Low levels of economic status and education contributed to the parent's refusal to accept explanations and make decisions to undergo surgery, and also because of the additional costs of surgery itself.

The therapeutic success rate and visual outcome of patients improved significantly in developed countries compared to developing countries. Chemotherapy followed by focal therapy has replaced the EBRT and provides a better outcome. However, the therapeutic success rate and visual outcome of patients in developing countries are low due to late diagnosis along with poor clinical conditions when patients are treated. $[11,12]$. In this study, patients still alive is found in 89 cases $(97.8 \%)$. The therapeutic success rate in this study is quite high due to a short follow up in 1-2 weeks. This is because RB patients at RSUP Haji Adam Malik Medan come from a remote area, and the difficulty to visit even a primary health facility in town generally causes the patient fail to follow up. The life expectancy of the patients is an important indicator because they generally come in an advanced state and follow-up is limited to only 1-2 weeks. The drawback of this study is the lack of completeness of medical record data so that follow up can only be assessed briefly for 1-2 weeks, in addition to its retrospective study design resulting in improper data recording.

In conclusion, $\mathrm{RB}$ patients referred to a tertiary hospital in a remote area in Indonesia are more likely to come in an advanced stage. They were from middle-income group parents, and there were more extraocular cases with major clinical features of protruded eye at an onset 2-3 years.

\section{References}

1. Corrêa ZM BJ. Retinoblastoma. American Academy of Ophthalmology. Availaible from: https://www.aao.org/ pediatric-center-detail/retinoblastoma-2016 [Accessed 30 Juli 2017].(2016). [

2. Mallipatna A, Marino M, Singh AD. Genetics of Retinoblastoma. Asia-Pacific journal of ophthalmology (Philadelphia, Pa). 2016;5(4):260-4.

3. Ali MJ, Honavar SG, Reddy VA. Orbital retinoblastoma: Present status and future challenges-A review. Saudi journal of ophthalmology: official journal of the Saudi Ophthalmological Society. 2011;25(2):159-67.

4. Aerts I, Lumbroso-Le Rouic L, Gauthier-Villars M, Brisse H, Doz F, Desjardins L. Retinoblastoma. Orphanet journal of rare diseases. 2006;1:31.

5. Organization WH. Review of Cancer Medicines on the WHO List of Essential Medicines. Retinoblastoma. In: Union for International Cancer Control 2014. ; (2014).

6. Mattosinho CCS, Grigorovski N, Lucena E, Ferman S, Soares de Moura ATM, Portes AF. Prediagnostic Intervals in Retinoblastoma: Experience at an Oncology Center in Brazil. Journal of global oncology. 2017;3(4):323-30.

7. Naseripour M. "Retinoblastoma survival disparity": The expanding horizon in developing countries. Saudi journal of ophthalmology : official journal of the Saudi Ophthalmological Society. 2012;26(2):157-61.

8. Pandey AN. Retinoblastoma: An overview. Saudi journal of ophthalmology : official journal of the Saudi Ophthalmological Society. 2014;28(4):310-5.

9. Dimaras H, Kimani K, Dimba EA, Gronsdahl P, White A, Chan HS, et al. Retinoblastoma. Lancet (London, England). 2012;379(9824):1436-46.

10. Meel R, Radhakrishnan V, Bakhshi S. Current therapy and recent advances in the management of retinoblastoma. Indian journal of medical and paediatric oncology : official journal of Indian Society of Medical \& Paediatric Oncology. 2012;33(2):80-8.

11. Ahmad A KF, Shamim W, Hanif A, Rodriguez-Galindo C Retinoblastoma-Clinical Spectrum and Treatment Outcome in Children. J of Rawalpindi Med Coll,. (2016).20,:198-1. 
12. Zimmermann K AR, Kuehni C, Geest SD,Cignacoo E. Malnutrition in pediatric patients with cancer at diagnosis and throughout therapy: A multicenter cohort study. Pediatr Blood Cancer (2012).

13. Tazi I, Hidane Z, Zafad S, Harif M, Benchekroun S, Ribeiro R. Nutritional status at diagnosis of children with malignancies in Casablanca. Pediatric blood \& cancer. 2008;51(4):495-8.

14. Dharmawidiarini D P, Soebagjo HD. Ocular Survival Rate Penderita Retinoblastoma yang Telah Dilakukan Enukleasi atau Eksenterasi di RSUD Dr. Soetomo Surabaya. J Oftalmol Indonesia,. (2010). ;7,:94-2.

15. Soebagjo HD PR, Sujuti H, Lyrawati D, Sumitro SB. Profile of Retinoblastoma in East Java, Indonesia. . World J of Med and Medical Sci Res,. (2013). ;1,:51-6.

16. Kaiser PK SI, O’brien JM, Murray TG Available from:http:// www.djo.harvard.edu/site.php?url=/patients/pi/436. 2014 [Accessed 30 Juli]. (2017) Retinoblastoma. [

17. Othman IS. Retinoblastoma major review with updates on Middle East management protocols. Saudi journal of ophthalmology: official journal of the Saudi Ophthalmological Society. 2012;26(2):163-75.

18. Ghassemi F CH, Sabour S, Karkhaneh R, Farzbod F, et al. Characteristic of Germline and Non-germline Retinoblastomas. . J Ophthalmic Vis Res, . (2014) 9,:188-4.

19. Luo C, Deng YP. Retinoblastoma: concerning its initiation and treatment. International journal of ophthalmology. 2013;6(3):397-401.

\section{(c) (1) (1)}

This work is licensed under a Creative Commons AttributionNon Commercial 4.0 International License. 